\title{
Enantioselective Separation of Mirtazapine and Its Metabolites by Capillary Electrophoresis with Acetonitrile Field-Amplified Sample Stacking and Its Application
}

\author{
Jun Wen ${ }^{1, \dagger}$, Wen-Ting Zhang ${ }^{1, \dagger}$, Wei-Qun Cao ${ }^{1, \dagger}, \mathrm{Ji} \mathrm{Li}^{2}$, Fang-Yuan Gao ${ }^{1}$, Nan Yang ${ }^{1}$ and \\ Guo-Rong Fan ${ }^{1, *}$
}

1 Department of Pharmaceutical Analysis, School of Pharmacy, Shanghai Key Laboratory for Pharmaceutical Metabolite Research, Second Military Medical University, Shanghai, 200433, China; E-Mails: wenjunapple@163.com (J.W.); zhangwt2011@163.com (W.-T.Z.); cao_weiqun@wuxiapptec.com (W.-Q.C.); gaofangyuan@outlook.com (F.-Y.G.); luckyyangnan123@163.com (N.Y.)

2 Department of Pharmacy, Kunming General Hospital of Chengdu Military Command, Kunming, 650032, China; E-Mail: gigiliji@163.com

$\dagger$ These authors contributed equally to this work.

* Author to whom correspondence should be addressed; E-Mail: guorfan@outlook.com; Tel.: +86-21-8187-1260; Fax: +86-21-8187-1260.

Received: 3 March 2014; in revised form: 10 April 2014 / Accepted: 14 April 2014 /

Published: 17 April 2014

\begin{abstract}
A simple, rapid and sensitive chiral capillary zone electrophoresis coupled with acetonitrile-field-amplified sample stacking method was developed that allows the simultaneous enantioselective separation of the mirtazapine, N-demethylmirtazapine, 8-hydroxymirtazapine and mirtazapine-N-oxide. The separation was achieved on an uncoated $40.2 \mathrm{~cm} \times 75 \mu \mathrm{M}$ fused silica capillary with an applied voltage of $16 \mathrm{kV}$. The electrophoretic analyses were carried out in $6.25 \mathrm{mM}$ borate- $25 \mathrm{mM}$ phosphate solution at $\mathrm{pH} 2.8$ containing $5.5 \mathrm{mg} / \mathrm{mL}$ carboxymethyl- $\beta$-cyclodextrin. The detection wavelength was $200 \mathrm{~nm}$. Under these optimized conditions, satisfactory chiral separations of four pair enantiomers were achieved in less than $7 \mathrm{~min}$ in vitro. After one step clean-up liquid-liquid extraction using 96-well format, sample was introduced capillary zone electrophoresis with acetonitrile-field-amplified sample stacking to enhance the sensitivity of enantiomers. The method was validated with respect to specificity, linearity, lower limit of quantitation, accuracy, precision, extraction recovery and stability. The lower limit of quantification was
\end{abstract}


$0.5 \mathrm{ng} / \mathrm{mL}$ with linear response over the $0.5-50 \mathrm{ng} / \mathrm{mL}$ concentration range for each mirtazapine, N-demethylmirtazapine and 8-hydroxymirtazapine enantiomer. The developed and validated method has been successfully applied to the enantioselective pharmacokinetic studies in 12 healthy volunteers after oral administration of rac- mirtazapine.

Keywords: chiral capillary zone electrophoresis; acetonitrile-field-amplified sample stacking; mirtazapine; N-demethylmirtazapine; 8-hydroxymirtazapine; liquid-liquid extraction

\section{Introduction}

Mirtazapine (MRT), whose chemical name is 1,2,3,4,10,14b-hexahydro-2-methylpyrazino[2,1-a] pyrido[2,3-c][2]benzazepine (Figure 1), is an effective tricyclic antidepressant combining two mechanisms of action: antagonizing the adrenergic $\mathrm{a}_{2}$-autoreceptors and $\mathrm{a}_{2}$-heteroreceptors as well as blocking postsynaptic serotonin $5-\mathrm{HT}_{2}$ and $5-\mathrm{HT}_{3}$ receptors. It also shows low affinity for $5-\mathrm{HT}_{1 \mathrm{~A}}$ receptors and therefore could enhance the release of norepinephrine and 5- $\mathrm{HT}_{1 \mathrm{~A}}-$ mediated serotonergic transmission. Thus, it is classified as a noradrenergic and specific serotonergic antidepressant (named as a NaSSA) [1-5]. It is also has been introduced in the veterinary field as an attractive ingredient to reduce pain, vomiting and to increase appetite in cats, dogs and horses [6-9]. Currently, MRT is marketed as the racemate and its $(-)-R$ and $(+)-S$-enantiomers have different pharmacologic and pharmacokinetic properties. The $(+)-S$-enantiomer shows a greater binding affinity than $(-)-R$-MRT in blocking $\mathrm{a}_{2}$-adrenergic auto receptor sand $5-\mathrm{HT}_{2}$, whereas the $\mathrm{a}_{2}$-adrenergic hetero receptor and $5-\mathrm{HT}_{3}$ type receptor blockading potencies reside predominantly in the $(-)$ - $R$-enantiomer. In addition, the enantioselective pharmacokinetics of MRT indicated the difference in half-life of the enantiomers. The elimination rate of the $(+)-S$-MRT was larger than that of the $(-)-R$-MRT after oral administration of the racemate $[10,11]$.

Figure 1. Chemical structures of (a) mirtazapine (MRT); (b) demethylmirtazapine (DMR); (c) 8-hydroxymirtazapine (8-OHM); (d) mirtazapine-N-oxide (N-O-MRT); (e) olanzapine (IS); $\left(^{*}\right)$ denotes a chiral center.

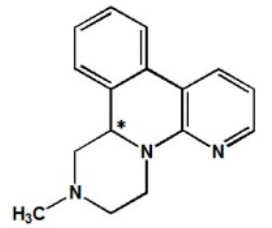

a

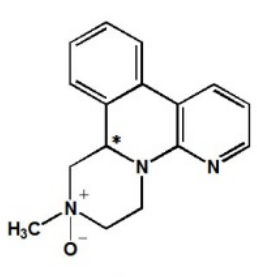

d<smiles>CN1CCN2C(=C3CN1CCN3c1ncccc1-c1ccccc1)c1ccccc1-c1cc(O)cnc12</smiles>

b

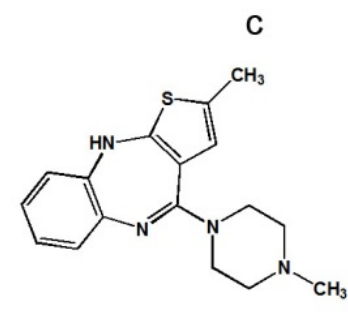

e 
Major pathways of biotransformation of MRT were demethylation with the formation of $\mathrm{N}$-demethylmirtazapine (DMR) and hydroxylation with the formation of 8-hydroxymirtazapine (8-OHM) followed by conjugation in humans. $\mathrm{N}$-oxide and $\mathrm{N}^{+}$-glucuronide of MRT were also found in plasma and urine after oral administration of MRT [12]. In vitro study demonstrated that enantioselective preference was shown by three cytochrome P450 enzymes, whereby $(+)-S$-MRT was metabolized extensively by CYP2D6 and to a relatively smaller extent by CYP1A2, and also to a relatively small extent (-)-R-MRT was metabolized by CYP3A4 [13].

Several analytical separation techniques had been reported for chiral separations of MRT alone or together with the metabolites in various biosamples, such as HPLC-UV [14-17], LC-FLD [18] and LC-MS/MS [19-21] on chiral column with cellulose or vancomycin as chiral stationary phase. In order to preconcentration and cleanup the biological fluids for simultaneous analysis of enantiomers, traditional sample preparation techniques including liquid-liquid extraction (LLE) [16,19], solid-phase extraction (SPE) [15,17] and protein precipitation [18] were used as well as some relative new techniques including liquid-phase microextraction (LPME) [14,21] and solid-phase microextraction (SPME) [20]. However the major drawback of these methods was the long analysis time (>15 min) except for a LC-MS/MS determination within 10 min described by de Santana [21]. In addition the sample preparation procedures were not only tedious and time consuming but also use larger volume of plasma or urine except protein precipitation.

On the other hand, capillary electrophoresis (CE) has become a promising, effective and economic approach in the field of chiral separation of drugs with various separation modes. It has several advantages compared to those techniques mentioned above, including high efficiency, rapid separation, low consumption of sample and separation electrolytes, and far cheaper capillaries. Hence CE method with carboxymethyl- $\beta$-cyclodextrin $(\mathrm{CM}-\beta-\mathrm{CD})$ as chiral selectors $[22,23]$ and capillary electrochromatography with vancomycin as chiral solid phase [24] were employed for the enantioselective separation of MRT and its metabolites. Mandrioli et al. [22] first reported a CE method to enantioseparate MRT and DMR in human plasma within a very brief time with a lower limit of quantification (LLOQ) of $7.5 \mathrm{ng} / \mathrm{mL}$. Of late, Malagueno et al. [23] have published a validated CE chiral method for the simultaneous analysis of the enantiomers of MRT, 8-OHM and DMR in human urine within $18 \mathrm{~min}$ with a limit of quantification (LOQ) of $62.5 \mathrm{ng} / \mathrm{mL}$. To overcome the drawback of the sensitivity in determination of the low concentration of the analytes in human plasma or urine by CE method, SPE [22,24] or LPME [23] was also developed for the purification and concentration of the biological samples by using high biological fluids volume.

An alternative approach to overcome the limit of sensitivity in CE was field amplified sample stacking (FASS) which was considered as a simple and efficient technique in capillary zone electrophoresis (CZE), first introduced by Mikkers et al. [25]. Shihabi [26] reported that organic solvent field amplified yields far better stacking than aqueous solvent field amplified for the compounds. Recently, our group has used acetonitrile field amplified sample stacking (ACN-FASS) technique for online concentration in CZE for the analysis some drugs in plasma [27,28]. Samples were dissolved in acetonitrile-water and then electrokinetically injected into the capillary. The conductivity of the samples was much lower than that of the background electrolyte (BGE) solution, resulting in enhanced electric field strength at the injection end. The analytes in the sample zone with high migration speed would decelerate sharply at the boundary of the running buffer, and therefore 
condensed at the interface between the low-conductivity zone and the running buffer [26,29]. The approach could effectively improve the sensitivity about 50-60 folds.

In this paper, we developed a CE method for the simultaneous enantioselective analysis of MRT and its three metabolites in vitro combined with ACN-FASS. Several parameters, such as type and concentration of chiral additives, $\mathrm{pH}$ and concentration of the BGE and applied voltage were studied for the rapid and sensitive chiral analysis optimization. One step plasma sample preparation by LLE in 96-well format was implemented to increase the throughput. After the sample preparation, N-O-MRT was not extracted from the plasma, which was coincided with the published article [19]. Thus, the method was validated for the simultaneous determination of MRT, DMR and 8-OHM enantiomers in human plasma, which offers lower LLOQ $(0.5 \mathrm{ng} / \mathrm{mL})$ with $200 \mu \mathrm{L}$ plasma for each enantiomers and short run time $(7 \mathrm{~min})$. The present method was applied to the enantioselective pharmacokinetic studies in 12 healthy volunteers after oral administration of $\mathrm{rac}$-MRT.

\section{Results and Discussion}

\subsection{Optimization of Enantioseparation Conditions}

\subsubsection{Type and Concentration}

The chiral separation in CE by the use of CDs utilizes the phenomenon of host-guest complexation with a relatively hydrophobic cavity, where a transient diastereomeric complex is formed between the chiral selector and the analytes [30]. In order to obtain simultaneous baseline resolution of four pair enantiomers, MRT, DMR, 8-OHM and N-O-MRT, $\beta-\mathrm{CD}$ and its derivatives were studied in our experiments as chiral selector according to the published papers [22,23]. Suitable chiral resolution was observed when using $C M-\beta-C D$, which coincided with these two papers.

As shown in Figure 2, with increasing CM- $\beta-C D$ concentrations from 3.0 to $5.5 \mathrm{mg} / \mathrm{mL}$, the migration time was prolonged. At the concentration of $5.5 \mathrm{mg} / \mathrm{mL}$, the resolution between pairs of enantiomers of rac-8-OHM, the most difficult to be separate, was improved and the reproducibility was better. When the concentration of $\mathrm{CM}-\beta-\mathrm{CD}$ was further increased, the resolution was slightly increased and the analysis time was longer. So the concentration of $5.5 \mathrm{mg} / \mathrm{mL}$ was selected as the optimal concentration.

\subsubsection{Optimization of Borate-Phosphate Buffer $\mathrm{pH}$ and Concentration and Applied Voltage}

MRT and its metabolites are basic drugs and they can be fully protonated in buffer at acidic $\mathrm{pH}$ values. Figure 3 showed that running buffer containing $6.25 \mathrm{mM}$ borate-25 mM phosphate solution and $5.5 \mathrm{mg} / \mathrm{mL} \mathrm{CM}-\beta-\mathrm{CD}$ was studied at different $\mathrm{pH}$ value. The increase of the $\mathrm{pH}$ from 2.8 to 3.6 prolonged the migration time and worsened the resolution. With a $\mathrm{pH}$ of 2.8 , better resolution and run time were obtained (Figure 3).

Different buffer solutions had different effects on the separation performance through its influence on the EOF and the current produced in the capillary [31]. The effect of concentration of borate-phosphate buffer ( $\mathrm{pH}$ 2.8) was studied. With the increasing buffer concentration, improved peak shape and resolution was obtained. 
Figure 2. Electropherograms of $\mathrm{rac}-\mathrm{MRT}(200 \mathrm{ng} / \mathrm{mL})$ and its metabolites standard with different chiral selectors (CM- $\beta$-CD) concentrations in the BGE: (a) $3.0 \mathrm{mg} / \mathrm{mL}$; (b) $4.0 \mathrm{mg} / \mathrm{mL}$; (c) $4.5 \mathrm{mg} / \mathrm{mL}$; (d) $5.0 \mathrm{mg} / \mathrm{mL}$; (e) $5.5 \mathrm{mg} / \mathrm{mL}$. Sample solvent: $10 \%$ buffer solution; Experimental conditions: running buffer: $25 \mathrm{mM}$ phosphate- $6.25 \mathrm{mM}$ borate (pH3.0); total uncoated capillary length: $40.2 \mathrm{~cm} \times 75 \mu \mathrm{M}$ i.d, effective length: $30.2 \mathrm{~cm}$; applied voltage: $16 \mathrm{kV}(+) \rightarrow(-)$; column temperature: $20{ }^{\circ} \mathrm{C}$; detection wavelength: $200 \mathrm{~nm}$; electrokinetic injection: $7.5 \mathrm{kV} \times 10 \mathrm{~s}$. Peaks: (1) (-)-R-DMR; (2) (-)-R-MRT; (3) (+)-S-DMR; (4) (+)-S-MRT; (5) (-)-R-8-OHM; (6) (+)-S-8-OHM; (7) (-)-R-N-O-MRT; (8) $(+)-S-N-O-M R T$.

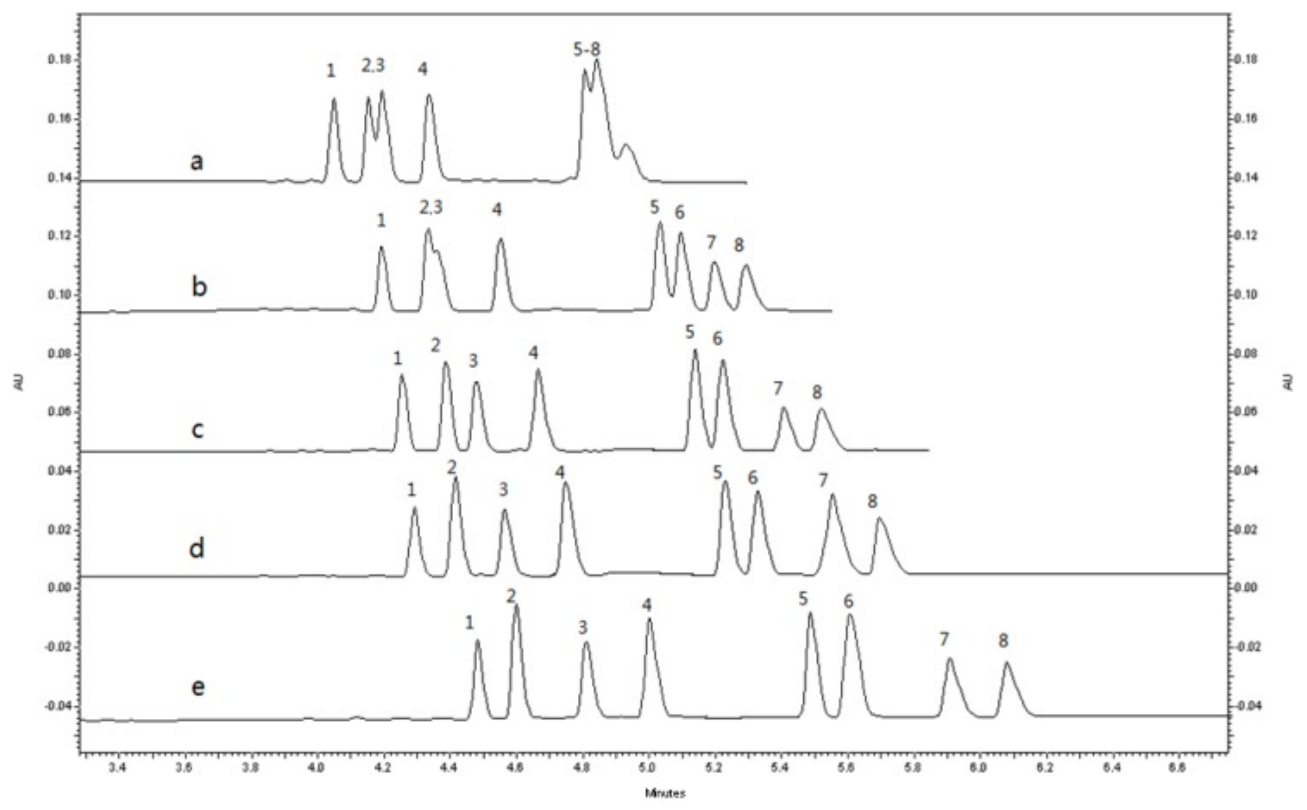

Figure 3. Electropherograms of $\mathrm{rac}-\mathrm{MRT}(200 \mathrm{ng} / \mathrm{mL})$ and its metabolites standard with different buffer $\mathrm{pH}$ : (a) $\mathrm{pH} 2.8$; (b) $\mathrm{pH} 3.0$; (c) $\mathrm{pH} 3.2$; (d) $\mathrm{pH} 3.4$; (e) $\mathrm{pH}$ 3.6. Peaks: (1) (-)-R-DMR; (2) (-)-R-MRT; (3) (+)-S-DMR; (4) (+)-S-MRT; (5) (-)-R-8-OHM; (6) $(+)-S-8-\mathrm{OHM}$; (7) (-)-R-N-O-MRT; (8) (+)-S-N-O-MRT. Other conditions see Figure 2.

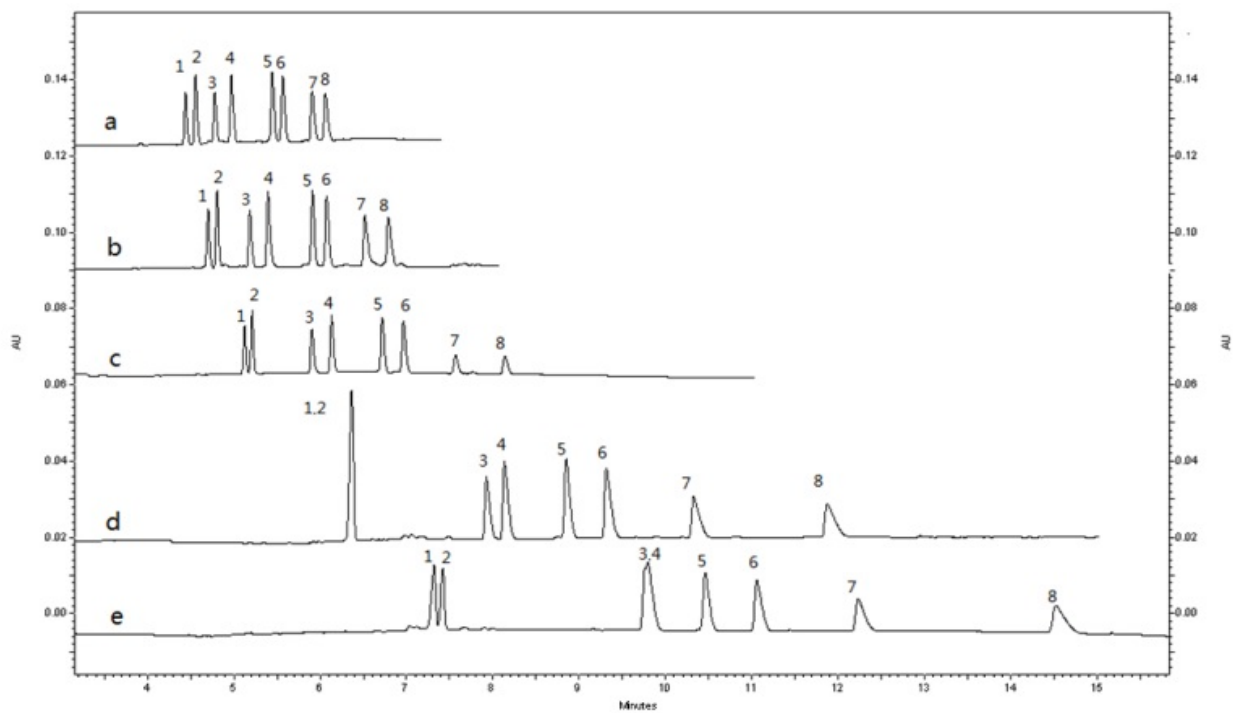


However, higher concentration might generate the increase in current and lower concentration meant lower conductivity resulted in loss in separation and sample stacking. Finally, $6.25 \mathrm{mM}$ borate- $25 \mathrm{mM}$ phosphate buffer solution was employed to achieve a good compromise between resolution, sensitivity and analysis time. Voltages over the range from 12 to $20 \mathrm{kV}$ were investigated. Too large of a separation voltage induced certain current problems, such as appreciable Joule heating and $16 \mathrm{kV}$ was chosen because it provided better performance.

\subsubsection{Optimization of Sample Stacking Performance}

\subsubsection{Selection of Injection Modes, Time and Voltage}

The analytes having higher $\mathrm{pKa}$ than the $\mathrm{pH}$ of the sample solution can be efficiently injected at positive polarity with electrokinetic injection [32] and sample stacking with electrokinetic injection provide larger sensitivity enhancements compared with hydrodynamic injection [33]. Therefore the electrokinetic injection was chosen as the optimum for the analysis of basic drugs in this experiment.

Electrokinetic injection sampling was used with solutes dissolved in $10 \%$ buffer $(6.25 \mathrm{mM}$ borate $-25 \mathrm{mM}$ phosphate ), and the injection time (5s-30 s) was tested with the injection voltage set at $3 \mathrm{kV}$. With increasing the injection time, the sensitivity was enhanced. Because of the overload of the sample with longer injection time, the response of analytes was reduced when the injection time was $>20 \mathrm{~s}$. So the injection time was set at $20 \mathrm{~s}$. With the $20 \mathrm{~s}$ injection time, different injection voltages $(3 \mathrm{kV}-10 \mathrm{kV})$ were studied and the similar results mentioned above was observed. The low conductivity of sample solution and high injection voltage might cause the current break down, which would lead to the failure of injection. As a compromise, $7.5 \mathrm{kV}$ was selected as the injection voltage.

\subsubsection{Selection of Sample Solvent}

The mechanism of ACN-FASS was creating a highly different fields strength between the sample zone and the separation electrolyte, which causes the analyte (cations) to experience high field strength, migrate rapidly and stack as a sharp band at the boundary buffer so as to bring along a focusing effect [34,35]. Increasing the difference of conductivity between sample solution and BGE could enhance the performance of sample stacking. Electropherograms for enantioseparation obtained after ACN-FASS are shown in Figure 4. There is about 50-60 times on the average increase in peak height due to the presence of ACN in the sample, which is similar to the results of some published papers [22-24]. Different ratios of $\mathrm{ACN}$ to distilled water $(70 \%, 80 \%, 90 \%)$ were also investigated. With the increase of ACN concentration, the analytes were stacked more effectively. However, 90\% ACN produced unstably current in CZE analysis, we chose $80 \% \mathrm{ACN}$-distilled water as sample solvent.

Figure 4a showed the typical electropherograms of enantioselective analysis of MRT and its three metabolites under the optimal conditions within $7 \mathrm{~min}$. The determination of the elution order using pure enantiomers was impossible because the individual standards of $S$ - and $R$-enantiomers of MRT and its metabolites were not commercially available. Thus, the migration order of rac-MRT and its metabolites were defined by some published papers that also used CM- $\beta-C D$ as chiral additives in BGE $[18,19]$. Under the adopted experimental conditions, the $(-)-R$-isomer migrated first and the $(+)-S$-isomer was the second migrating peak both for the drug and the metabolites. 
Figure 4. The effect of different sample solvents on FASS of $r a c$-MRT $(50 \mathrm{ng} / \mathrm{mL})$ and its metabolites standard. Running buffer: $25 \mathrm{mM}$ phosphate-6.25 Mm borate (pH 2.8) with 5.5 mg/mL CM- $\beta$-CD; Electropherograms: (a) 80\% ACN-distilled water; (b) distilled water; (c) 10\% buffer. Peaks: (1) (-)-R-DMR; (2) (-)-R-MRT; (3) (+)-S-DMR; (4) (+)-S-MRT; (5) (-)-R-8-OHM; (6) (+)-S-8-OHM; (7) (-)-R-N-O-MRT; (8) (+)-S-N-O-MRT. Other conditions see Figure 2.

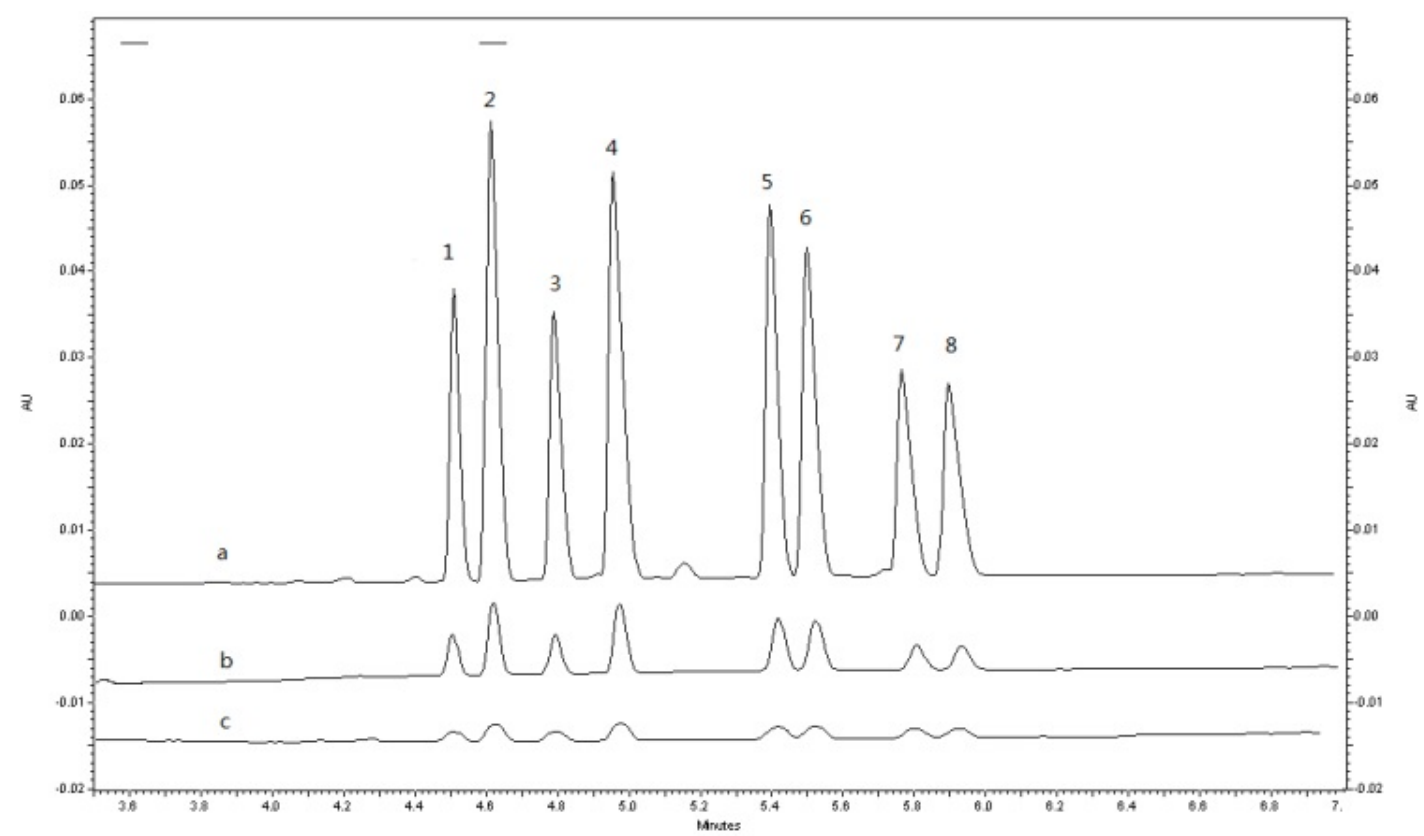

\subsubsection{Sample Preparation}

According to the method described in references [16,19], one step LLE for the extraction of plasma samples was optimized in our preliminary studies. Ethyl acetate and methyl tert-butyl ether were tested as the extraction solvent. The latter was adopted because of its high extraction efficiency and efficient sample clean-up results. A $20 \mu \mathrm{L}$ aliquot of $1 \mathrm{~mol} / \mathrm{L} \mathrm{NaOH}$ was added to $200 \mu \mathrm{L}$ plasma spiked with $20 \mu \mathrm{L}$ internal standard (IS) solution (200 ng/mL olanzapine), which avoided analytes protonation during extraction. In order to increase sample throughput, the LLE 96-well plates were used, resulting in a shorter sample preparation time.

\subsection{Method Validation}

\subsubsection{Specificity}

Specificity of the method was investigated by blank plasma, blank plasma spiked with rac-MRT, $r a c-D M R, r a c-8-O H M$ at LLOQ of $1 \mathrm{ng} / \mathrm{mL}$, and a real human plasma sample to discriminate the analyte from all potentially interfering substance. As shown in Figure 5, there was no significant interference from endogenous substances observed at the retention times of the analytes. The extraction procedure of plasma samples spiked $1 \mathrm{ng} / \mathrm{mL}$ and $100 \mathrm{ng} / \mathrm{mL}$ rac-N-O-MRT showed that $\mathrm{N}-\mathrm{O}-\mathrm{MRT}$ was not extracted, which was coincided with the published article [19] and the method was not further validated for the enantiomers N-O-MRT in human plasma. 
Figure 5. Typical electropherograms: (a) test sample of human treated with rac-MRT $0.5 \mathrm{~h}$ after the dose of $30 \mathrm{mg}$; (b) blank plasma spiked with $1 \mathrm{ng} / \mathrm{mL}$ (LLOQ) rac-MRT, rac-DMR, rac-8-OHM and $20 \mathrm{ng} / \mathrm{mL}$ IS; (c) blank plasma. Peaks: (1) (-)- $R$-DMR; (2) (-)-R-MRT; (3) (+)-S-DMR; (4) (+)-S-MRT; (5) (-)-R-8-OHM; (6) (+)-S-8-OHM.

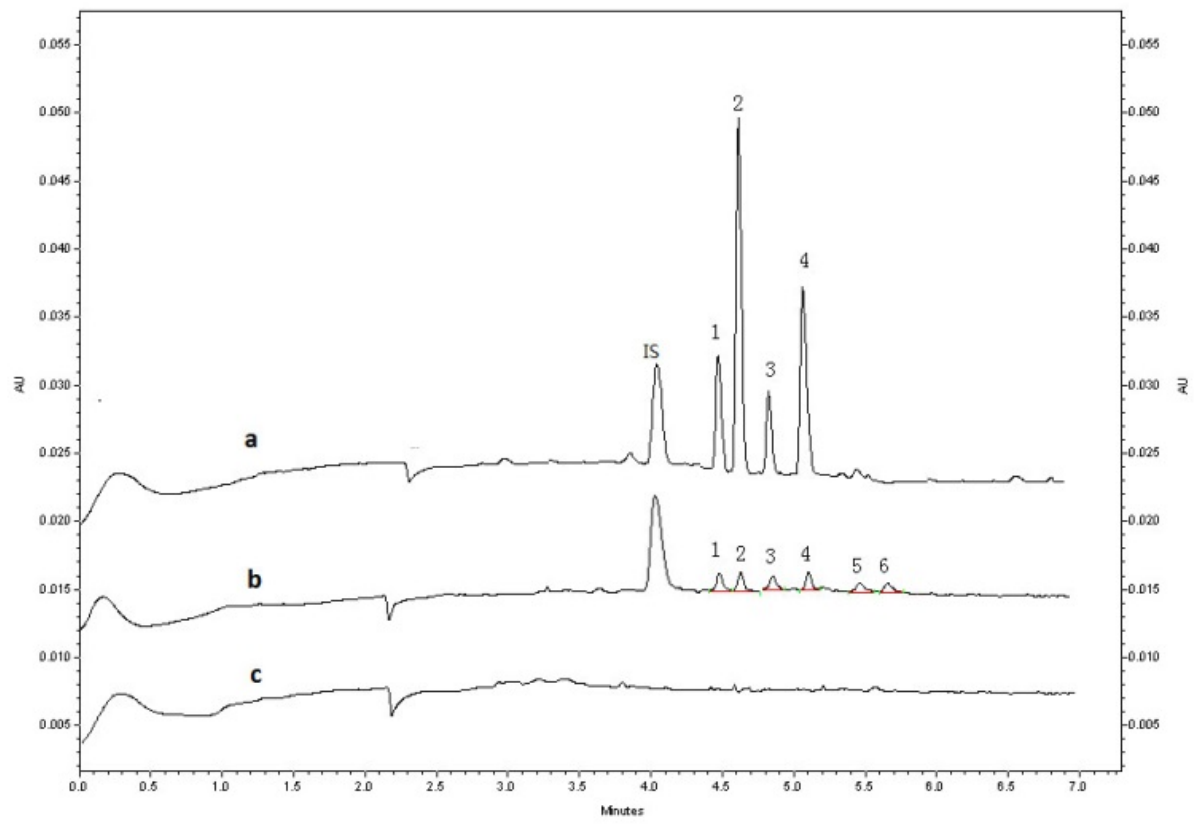

2.2.2. Linearity of Calibration Curves and Lower Limits of Quantification

A series of different concentrations of $200 \mu \mathrm{L}$ drug free plasma samples spiked with 1, 2, 5, 10, 20, 50 and $100 \mathrm{ng} / \mathrm{mL}$ of $r a c-M R T$, rac-DMR and rac-8-OHM $(\mathrm{n}=3)$ were analyzed to determine the linear response range. The calibration curves were generated by the peak area ratios of each enantiomer to IS versus the concentration of the half of the concentration of racemate spiked in the samples. A weighted (1/x) linear regression was used to perform standard calibration. Table 1 showed excellent linearity in the range $0.5-50 \mathrm{ng} / \mathrm{mL}$ of each MRT, DMR and 8-OHM enantiomer. The LLOQ of the assay was determined as the lowest concentration on the standard curve that could be quantitated with a precision of $20 \%$ and accuracy within $\pm 20 \%$. The LLOQ of MRT, DMR and 8-OHM enantiomers in human plasma was found to be $0.5 \mathrm{ng} / \mathrm{mL}$ with accuracy ranged from $-10.8 \%$ to $10.4 \%$ and precision of $14 \%$ over five analytical runs.

\subsubsection{Accuracy, Precision and Extraction Recovery}

Five replicate samples of quality control (QC) at three levels (low, medium, and high concentrations, $1,5,40 \mathrm{ng} / \mathrm{mL}$ ) were analyzed in three separate runs. Precision was determined by calculating the coefficient of variation for within- and between-run replicates. Accuracy was assessed by calculating the percentage deviation from the spiked concentration. Tables 2 and 3 showed that the within-day variances for all compounds were lower than $14.2 \%$ and all between-day variances were below $12.9 \%$. It was shown that the within- and between-day accuracies were found to be within $10.4 \%$ and $-10.8 \%$ for all the enantiomers 
Table 1. The calibration equations for the determination of MRT, DMR, 8-OHM enantiomers $(\mathrm{n}=3)$.

\begin{tabular}{cccccc}
\hline Enantiomer & $\begin{array}{c}\text { Range(ng/ } \\
\mathbf{m L})\end{array}$ & $\begin{array}{c}\text { Regression } \\
\text { Equations }\end{array}$ & $\begin{array}{c}\text { Correlation } \\
\text { Coefficient(R }\end{array}$ & $\begin{array}{c}\text { SD for the } \\
\text { Slope }\end{array}$ & $\begin{array}{c}\text { SD for the } \\
\text { Inercept }\end{array}$ \\
\hline$(-)-R$-MRT & $0.5-50$ & $\mathrm{y}=0.256 \mathrm{x}+0.0188$ & 0.998 & 0.050 & 0.027 \\
$(+)-S$-MRT & $0.5-50$ & $\mathrm{y}=0.232 \mathrm{x}+0.0156$ & 0.992 & 0.048 & 0.015 \\
$(-)-R$-DMR & $0.5-50$ & $\mathrm{y}=0.315 \mathrm{x}-0.0314$ & 0.995 & 0.037 & 0.030 \\
$(+)-S$-DMR & $0.5-50$ & $\mathrm{y}=0.290 \mathrm{x}-0.0290$ & 0.993 & 0.041 & 0.020 \\
$(-)-R-8-\mathrm{OHM}$ & $0.5-50$ & $\mathrm{y}=0.145 \mathrm{x}-0.0517$ & 0.995 & 0.044 & 0.030 \\
$(+)-S-8-\mathrm{OHM}$ & $0.5-50$ & $\mathrm{y}=0.130 \mathrm{x}-0.0444$ & 0.994 & 0.039 & 0.033 \\
\hline
\end{tabular}

Table 2. Within-day precision and accuracy for the analysis of MRT, DMR and 8-OHM enantiomers in human plasma $(\mathrm{n}=5)$.

\begin{tabular}{|c|c|c|c|c|c|c|c|c|c|c|c|c|}
\hline \multirow{2}{*}{ Enantiomer } & \multicolumn{3}{|c|}{$\begin{array}{c}\text { LLOQ } \\
0.5 \mathrm{ng} / \mathrm{mL} \\
\end{array}$} & \multicolumn{3}{|c|}{$\begin{array}{c}\text { Low QC } \\
1 \mathrm{ng} / \mathrm{mL}\end{array}$} & \multicolumn{3}{|c|}{$\begin{array}{c}\text { Medium QC } \\
5 \mathrm{ng} / \mathrm{mL} \\
\end{array}$} & \multicolumn{3}{|c|}{$\begin{array}{l}\text { High QC } \\
40 \mathrm{ng} / \mathrm{mL}\end{array}$} \\
\hline & $\begin{array}{c}\text { Mean } \pm \text { SD } \\
(\mathrm{ng} / \mathrm{mL})\end{array}$ & $\begin{array}{l}\text { RE } \\
(\%)\end{array}$ & $\begin{array}{c}\text { RSD } \\
(\%)\end{array}$ & $\begin{array}{c}\text { Mean } \pm \text { SD } \\
(\mathrm{ng} / \mathrm{mL})\end{array}$ & $\begin{array}{l}\mathrm{RE} \\
(\%)\end{array}$ & $\begin{array}{c}\text { RSD } \\
(\%)\end{array}$ & $\begin{array}{c}\text { Mean } \pm \text { SD } \\
(\mathrm{ng} / \mathrm{mL})\end{array}$ & $\begin{array}{l}\text { RE } \\
(\%)\end{array}$ & $\begin{array}{c}\text { RSD } \\
(\%)\end{array}$ & $\begin{array}{c}\text { Mean } \pm \text { SD } \\
(\mathrm{ng} / \mathrm{mL})\end{array}$ & $\begin{array}{l}\mathrm{RE} \\
(\%)\end{array}$ & $\begin{array}{r}\text { RSD } \\
(\%) \\
\end{array}$ \\
\hline$(-)-R-\mathrm{MRT}$ & $0.54 \pm 0.041$ & 8.0 & 8.2 & $1.08 \pm 0.12$ & 7.8 & 11.3 & $5.16 \pm 0.36$ & 3.3 & 7.0 & $40.34 \pm 1.4$ & 0.8 & 3.4 \\
\hline$(+)-S$-MRT & $0.46 \pm 0.060$ & -8.1 & 14.0 & $0.99 \pm 0.10$ & -1.2 & 10.0 & $4.88 \pm 0.33$ & -2.4 & 6.7 & $39.32 \pm 1.3$ & -1.7 & 3.4 \\
\hline$(-)-R-\mathrm{DMR}$ & $0.55 \pm 0.069$ & 10.4 & 13.2 & $1.03 \pm 0.15$ & 2.7 & 14.2 & $4.61 \pm 0.27$ & -7.9 & 6.0 & $39.57 \pm 1.2$ & -1.1 & 3.0 \\
\hline$(+)-S-D M R$ & $0.49 \pm 0.052$ & -2.2 & 9.2 & $1.04 \pm 0.11$ & 3.7 & 10.8 & $5.08 \pm 0.25$ & 1.6 & 4.9 & $39.28 \pm 1.5$ & -1.8 & 3.9 \\
\hline$(-)-R-8-\mathrm{OHM}$ & $0.45 \pm 0.041$ & -10.8 & 7.9 & $0.97 \pm 0.09$ & -3.4 & 9.7 & $4.68 \pm 0.30$ & -6.3 & 6.3 & $43.68 \pm 1.8$ & 9.2 & 4.0 \\
\hline$(+)-S-8-O H M$ & $0.54 \pm 0.041$ & 7.6 & 8.2 & $0.95 \pm 0.08$ & -4.8 & 8.8 & $5.35 \pm 0.28$ & 6.9 & 5.3 & $39.94 \pm 0.95$ & -0.2 & 2.4 \\
\hline
\end{tabular}


Table 3. Between-day precision and accuracy for the analysis of MRT, DMR and 8-OHM enantiomers in human plasma $(n=15)$.

\begin{tabular}{|c|c|c|c|c|c|c|c|c|c|}
\hline \multirow{2}{*}{ Enantiomer } & \multicolumn{3}{|c|}{$\begin{array}{l}\text { Low QC } \\
1 \text { ng/mL }\end{array}$} & \multicolumn{3}{|c|}{$\begin{array}{c}\text { Medium QC } \\
5 \mathrm{ng} / \mathrm{mL} \\
\end{array}$} & \multicolumn{3}{|c|}{$\begin{array}{l}\text { High QC } \\
40 \mathrm{ng} / \mathrm{mL} \\
\end{array}$} \\
\hline & $\begin{array}{c}\text { Mean } \pm \text { SD } \\
(\mathbf{n g} / \mathbf{m L})\end{array}$ & $\begin{array}{l}\text { RE } \\
(\%) \\
\end{array}$ & $\begin{array}{l}\text { RSD } \\
(\%)\end{array}$ & $\begin{array}{c}\text { Mean } \pm \text { SD } \\
(\mathrm{ng} / \mathrm{mL})\end{array}$ & $\begin{array}{l}\mathrm{RE} \\
(\%) \\
\end{array}$ & $\begin{array}{l}\text { RSD } \\
(\%)\end{array}$ & $\begin{array}{c}\text { Mean } \pm \text { SD } \\
(\mathrm{ng} / \mathrm{mL})\end{array}$ & $\begin{array}{l}\text { RE } \\
(\%) \\
\end{array}$ & $\begin{array}{l}\text { RSD } \\
(\%)\end{array}$ \\
\hline$(-)-R$-MRT & $1.04 \pm 0.11$ & 4.3 & 10.2 & $5.10 \pm 0.36$ & 2.1 & 7.1 & $41.26 \pm 1.8$ & 3.1 & 4.3 \\
\hline$(+)-S$-MRT & $0.99 \pm 0.10$ & 1.0 & 9.5 & $4.98 \pm 0.32$ & -0.5 & 6.5 & $39.69 \pm 1.4$ & -0.8 & 3.6 \\
\hline$(-)-R$-DMR & $1.07 \pm 0.14$ & 6.8 & 12.9 & $4.86 \pm 0.33$ & -2.6 & 6.8 & $39.70 \pm 1.3$ & -0.8 & 3.2 \\
\hline$(+)-S$-DMR & $1.02 \pm 0.10$ & 1.6 & 9.6 & $5.05 \pm 0.29$ & 0.9 & 5.7 & $39.08 \pm 1.5$ & -2.2 & 3.9 \\
\hline$(-)-R-8-\mathrm{OHM}$ & $0.93 \pm 0.10$ & -6.7 & 10.8 & $4.92 \pm 0.35$ & -1.6 & 7.2 & $42.83 \pm 1.8$ & 7.1 & 4.1 \\
\hline$(+)-S-8-O H M$ & $0.99 \pm 0.09$ & -0.6 & 9.0 & $5.14 \pm 0.31$ & 2.8 & 6.1 & $40.61 \pm 1.5$ & 1.5 & 3.6 \\
\hline
\end{tabular}

The extraction recovery of MRT, DMR and 8-OHM enantiomers was determined by comparing the peak area of the QCs with the peak area of the corresponding standard solution spiked in extracted blank plasma. The recovery of IS was determined similarly. Table 4 showed the extraction recoveries were found to be all above $80 \%$ at three QC levels of MRT, DMR and 8-OHM enantiomers and the one of IS was $81.6 \%$.

Table 4. Recoveries of MRT, DMR and 8-OHM enantiomers in human plasma $(n=5)$.

\begin{tabular}{|c|c|c|c|}
\hline Enantiomer & $\begin{array}{c}\text { Concentration } \\
(\mathrm{ng} / \mathrm{mL})\end{array}$ & $\begin{array}{c}\text { Recovery (\%) } \\
(\text { mean } \pm \text { SD) }\end{array}$ & RSD (\%) \\
\hline \multirow[t]{3}{*}{$(-)-R$-MRT } & 1 & $86.7 \pm 8.9$ & 10.3 \\
\hline & 5 & $89.4 \pm 5.7$ & 6.4 \\
\hline & 40 & $90.2 \pm 4.8$ & 5.3 \\
\hline \multirow[t]{3}{*}{$(+)-S$-MRT } & 1 & $87.7 \pm 7.3$ & 8.4 \\
\hline & 5 & $90.1 \pm 3.9$ & 4.3 \\
\hline & 40 & $92.0 \pm 5.4$ & 5.9 \\
\hline \multirow[t]{3}{*}{$(-)-R$-DMR } & 1 & $82.8 \pm 8.6$ & 10.4 \\
\hline & 5 & $87.5 \pm 7.6$ & 8.7 \\
\hline & 40 & $87.5 \pm 3.0$ & 3.4 \\
\hline \multirow[t]{3}{*}{$(+)-S$-DMR } & 1 & $83.5 \pm 6.8$ & 8.2 \\
\hline & 5 & $85.8 \pm 8.9$ & 10.3 \\
\hline & 40 & $88.9 \pm 3.7$ & 4.1 \\
\hline \multirow[t]{3}{*}{ (+)-R-8-OHM } & 1 & $81.8 \pm 5.9$ & 7.3 \\
\hline & 5 & $85.1 \pm 8.7$ & 10.2 \\
\hline & 40 & $89.5 \pm 2.3$ & 2.5 \\
\hline \multirow[t]{3}{*}{$(+)-S-8-\mathrm{OHM}$} & 1 & $83.2 \pm 9.6$ & 11.5 \\
\hline & 5 & $86.1 \pm 7.5$ & 8.8 \\
\hline & 40 & $87.8 \pm 4.4$ & 5.0 \\
\hline
\end{tabular}

\subsubsection{Stability}

Analyte stability determinations comprised short-term temperature stability, long-term stability, autosampler stability and freeze-thaw cycles stability, which were evaluated by analyzing three QC 
levels in quintuple. The peak areas obtained from both stability tests were compared with the peak areas obtained with freshly prepared samples. The mean values and standard deviations of the ratios between the concentrations found and initial concentration were used for stability evaluation. Table 5 showed that MRT, DMR and 8-OHM enantiomers in the spiked plasma samples were found to be stable in the experimental conditions assayed.

Table 5. Stability results of MRT, DMR and 8-OHM enantiomers in spiked plasma samples $(\mathrm{n}=3)$.

\begin{tabular}{|c|c|c|c|c|c|c|c|c|c|}
\hline \multirow[b]{2}{*}{ Enantiomer } & \multirow[b]{2}{*}{$\begin{array}{c}\text { Nominal } \\
\text { Concentration } \\
(\mathbf{n g} / \mathbf{m L})\end{array}$} & \multicolumn{2}{|c|}{ Freeze-Thaw Stability ${ }^{a}$} & \multicolumn{2}{|c|}{ 30-Day Stability ${ }^{\mathrm{b}}$} & \multicolumn{2}{|c|}{ Bench Top Stability ${ }^{c}$} & \multicolumn{2}{|c|}{ Autosampler Stability ${ }^{\text {d }}$} \\
\hline & & $\begin{array}{c}\text { Measured } \\
\text { Concentration } \\
(\mathrm{ng} / \mathrm{mL}) \\
(\mathrm{mean} \pm \mathrm{SD}) \\
\end{array}$ & $\begin{array}{l}\text { RSD } \\
(\%)\end{array}$ & $\begin{array}{c}\text { Measured } \\
\text { Concentration } \\
(\mathrm{ng} / \mathrm{mL}) \\
(\mathrm{mean} \pm \mathrm{SD}) \\
\end{array}$ & $\begin{array}{l}\text { RSD } \\
(\%)\end{array}$ & $\begin{array}{c}\text { Measured } \\
\text { Concentration } \\
(\mathbf{n g} / \mathbf{m L}) \\
(\text { mean } \pm \text { SD) }\end{array}$ & $\begin{array}{l}\text { RSD } \\
(\%)\end{array}$ & $\begin{array}{c}\text { Measured } \\
\text { Concentration } \\
(\mathrm{ng} / \mathrm{mL}) \\
(\text { mean } \pm \text { SD) } \\
\end{array}$ & $\begin{array}{l}\text { RSD } \\
\text { (\%) }\end{array}$ \\
\hline \multirow{3}{*}{$(-)-R$-MRT } & 1 & $0.99 \pm 0.11$ & 11.5 & $1.08 \pm 0.12$ & 10.8 & $1.04 \pm 0.12$ & 11.8 & $0.99 \pm 0.10$ & 9.7 \\
\hline & 5 & $4.70 \pm 0.25$ & 5.4 & $4.98 \pm 0.29$ & 5.8 & $5.33 \pm 0.29$ & 5.5 & $5.13 \pm 0.31$ & 5.9 \\
\hline & 40 & $37.61 \pm 2.0$ & 5.4 & $41.96 \pm 1.3$ & 3.0 & $41.33 \pm 2.3$ & 5.5 & $38.34 \pm 1.4$ & 3.6 \\
\hline \multirow{3}{*}{$(+)-S$-MRT } & 1 & $0.95 \pm 0.09$ & 9.7 & $1.07 \pm 0.12$ & 1.6 & $1.02 \pm 0.12$ & 12.3 & $1.03 \pm 0.12$ & 11.8 \\
\hline & 5 & $5.06 \pm 0.35$ & 6.9 & $4.89 \pm 0.28$ & 5.8 & $5.08 \pm 0.30$ & 5.8 & $5.06 \pm 0.30$ & 5.9 \\
\hline & 40 & $38.6 \pm 1.8$ & 4.7 & $42.5 \pm 2.1$ & 5.0 & $44.0 \pm 1.6$ & 3.7 & $36.3 \pm 1.9$ & 3.5 \\
\hline \multirow{3}{*}{$(-)-R$-DMR } & 1 & $0.91 \pm 0.079$ & 8.6 & $1.08 \pm 0.12$ & 10.8 & $1.02 \pm 0.088$ & 9.1 & $1.03 \pm 0.078$ & 8.2 \\
\hline & 5 & $4.98 \pm 0.25$ & 5.1 & $4.63 \pm 0.23$ & 4.9 & $5.33 \pm 0.29$ & 5.5 & $4.86 \pm 0.26$ & 5.4 \\
\hline & 40 & $39.20 \pm 2.1$ & 5.2 & $37.26 \pm 1.8$ & 4.7 & $40.55 \pm 2.6$ & 6.3 & $39.00 \pm 2.0$ & 5.0 \\
\hline \multirow{3}{*}{ (+)-S-DMR } & 1 & $1.03 \pm 0.12$ & 11.1 & $1.07 \pm 0.12$ & 11.6 & $1.00 \pm 0.070$ & 6.8 & $1.03 \pm 0.12$ & 11.7 \\
\hline & 5 & $4.65 \pm 0.28$ & 6.0 & $4.52 \pm 0.26$ & 5.7 & $5.40 \pm 0.34$ & 6.2 & $4.98 \pm 0.25$ & 4.9 \\
\hline & 40 & $39.20 \pm 2.1$ & 5.2 & $39.98 \pm 2.3$ & 5.6 & $36.51 \pm 1.4$ & 3.9 & $40.61 \pm 1.5$ & 3.6 \\
\hline \multirow{3}{*}{$(-)-R-8-\mathrm{OHM}$} & 1 & $0.91 \pm 0.081$ & 8.6 & $1.02 \pm 0.11$ & 10.5 & $1.13 \pm 0.10$ & 9.2 & $0.95 \pm 0.09$ & 9.4 \\
\hline & 5 & $5.12 \pm 0.22$ & 4.3 & $5.07 \pm 0.18$ & 3.6 & $4.99 \pm 0.25$ & 4.9 & $5.31 \pm 0.36$ & 6.8 \\
\hline & 40 & $39.55 \pm 0.93$ & 2.4 & $40.4 \pm 2.0$ & 4.8 & $42.9 \pm 1.8$ & 4.1 & $40.0 \pm 2.0$ & 4.9 \\
\hline \multirow{3}{*}{ (+)-S-8-OHM } & 1 & $0.97 \pm 0.11$ & 10.9 & $1.01 \pm 0.09$ & 8.5 & $1.02 \pm 0.12$ & 12.3 & $0.98 \pm 0.11$ & 10.8 \\
\hline & 5 & $5.10 \pm 0.20$ & 3.9 & $5.06 \pm 0.19$ & 3.7 & $5.04 \pm 0.27$ & 5.3 & $4.93 \pm 0.34$ & 6.8 \\
\hline & 40 & $40.12 \pm 2.0$ & 5.0 & $40.71 \pm 1.3$ & 3.2 & $42.55 \pm 1.8$ & 4.1 & $38.72 \pm 1.8$ & 4.7 \\
\hline
\end{tabular}

${ }^{\mathrm{a}}$ After three freeze-thaw cycles.; ${ }^{\mathrm{b}}$ Stored at $-20{ }^{\circ} \mathrm{C}$; ${ }^{\mathrm{c}}$ Exposed at ambient temperature $\left(25{ }^{\circ} \mathrm{C}\right)$ for $8 \mathrm{~h}$.;

${ }^{\mathrm{d}}$ Kept at ambient temperature $\left(25^{\circ} \mathrm{C}\right)$ for $8 \mathrm{~h}$.

\subsection{Application to Pharmacokinetic Studies}

8-OHM was only detected in plasma at $1 \mathrm{~h}$ in two volunteers following oral administration of MRT. The majority of plasma samples had no detectable levels of 8 -OHM. The reason could be that conjugated 8-OHM was predominantly found in plasma and hydrolysis reaction should be implemented for the assay of 8-OHM in plasma [12,14,20]. Figure 6 represents mean plasma concentration profile of MRT, and DMR enantiomers versus time in these volunteers. The maximum concentration of (-)-R-and (+)-S-MRT were found at approximately $1.5 \mathrm{~h}$ after the administration of rac-MRT. The concentration-time courses of the individual enantiomers of MRT in plasma were distinctly different. Although the plasma concentration of $(+)-S$-DMR was similar to that of $(-)-R$-DMR at each time point, the $S / R$-ratios of DMR were $<1$ in all human subjects. The mean 
$\mathrm{AUC}_{0-\infty}$ values of $(-)$ - $R$-enantiomers were significant higher $(p<0.05)$ than that of $(+)$-S-enantiomers for both MRT and DMR by an independent-measures t-test. Pharmacokinetic parameters estimated by the non-compartmental approach are listed in Table 6 . These values were in agreement with previously published data $[12,19]$.

Figure 6. Mean plasma concentration-time profiles for MRT and DMR enantiomers in 12 healthy male volunteers following oral administration of rac-MRT $30 \mathrm{mg}$.

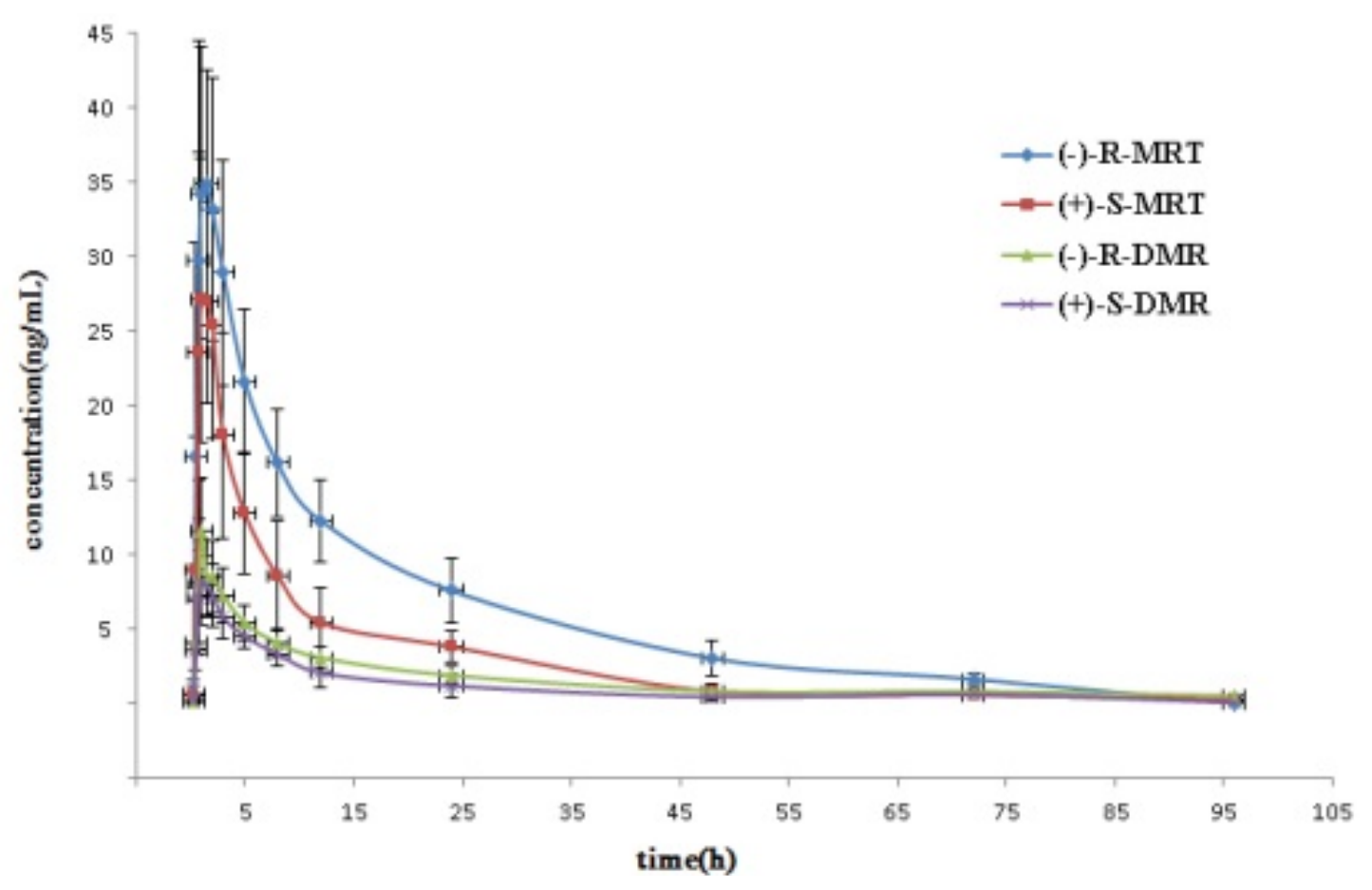

Table 6. Pharmacokinetic parameters of the enantiomers of MRT and DMR after oral administration of $\mathrm{rac}$-MRT $30 \mathrm{mg}$ to 12 healthy volunteers.

\begin{tabular}{|c|c|c|c|c|c|c|}
\hline Enantiomer & $C_{\max }(\mathrm{ng} / \mathrm{mL})$ & $\mathbf{T}_{\max }(\mathbf{h})$ & $t_{1 / 2}(h)$ & MRT * (h) & $\operatorname{AUC}_{0-96}(\mathrm{ng} \mathrm{h} / \mathrm{mL})$ & $\operatorname{AUC}_{0-\infty}(\mathrm{ng} \mathrm{h} / \mathbf{m L})$ \\
\hline$(-)-R-\mathrm{MRT}$ & $41.81 \pm 4.1$ & $1.42 \pm 0.66$ & $23.22 \pm 4.9$ & $27.37 \pm 5.5$ & $570.94 \pm 98$ & $613.84 \pm 103$ \\
\hline$(+)-S$-MRT & $34.15 \pm 5.9$ & $1.30 \pm 0.71$ & $15.54 \pm 4.4$ & $17.43 \pm 4.0$ & $276.94 \pm 76$ & $284.14 \pm 74$ \\
\hline$(-)-R$-DMR & $12.73 \pm 2.5$ & $1.32 \pm 0.54$ & $19.80 \pm 4.3$ & $22.55 \pm 5.7$ & $133.75 \pm 36$ & $149.83 \pm 39$ \\
\hline$(+)-S$-DMR & $10.02 \pm 1.8$ & $1.29 \pm 0.73$ & $11.45 \pm 3.3$ & $17.90 \pm 4.5$ & $96.10 \pm 34$ & $109.84 \pm 36$ \\
\hline
\end{tabular}

* MRT, mean residence time, represents the average time the drug molecule stays in the body.

\section{Experimental}

\subsection{Chemicals and Reagents}

Racemic MRT (98.0\% purity) (Figure 1) was purchased from Sigma-Aldrich (St. Louis, MO, USA). Racemic DMR, 8-OHM and N-O-MRT (Figure 1) were supplied by Toronto Research Chemicals Inc (North York, ON, Canada). Olanzapine (99.0\% purity, internal standard, Figure 1) was obtained from National Institute for the Control of Pharmaceutical and Biological Product (Beijing, China). CM- $\beta$-CD sodium salt (degree of substitution, DS 3.5) was purchased from Cyclodextrin Research \& Development Laboratory (Buchs, Switzerland). Sodium dihydrogenphosphate and sodium tetraborate 
were acquired from China Medicine (Group) Shanghai Chemical Reagent Corporation (Shanghai, China). Phosphoric acid was from Sigma (St. Louis, MO, USA). ACN and methyl tert-butyl ether were from J.T. Baker (Phillipsburg, NJ, USA). All chemicals were analytical grade or better. Human control plasma (sodium heparin as an anticoagulant) was obtained from Shanghai Shuguang Hospital (Shanghai, China). Deionized water $(18.2 \mathrm{M} \Omega \mathrm{cm}$ ) was obtained by using a Milli-Q system (Millipore, Milford, MA, USA).

\subsection{Apparatus and Capillary Electrophoretic Conditions}

All assays were performed on a CE system consisted of a Beckman P/ACE MDQ instrument (Beckman Coulter, Brea, CA, USA) equipped with a photodiode array detection detector (PDA) and $\mathrm{P} / \mathrm{ACE}$ System MDQ Software. Data collection, processing, and analysis were performed using system 32-Karat software (Beckman). An uncoated fused-silica capillary (Yongnian Optical Fiber Factory, Hebei, China) of $75 \mu \mathrm{M}$ i.d., $40.2 \mathrm{~cm}$ in total length, and $30.2 \mathrm{~cm}$ in effective length was used. Detection was performed at $200 \mathrm{~nm}$, where the samples had the maximum absorption.

The BGE solution used in this study was composed of $6.25 \mathrm{mM}$ borate- $25 \mathrm{mM}$ phosphate (pH 2.8) and $5.5 \mathrm{mg} / \mathrm{mL} \mathrm{CM}-\beta-\mathrm{CD}$. It was prepared by accurately weighing $0.39 \mathrm{~g}$ phosphate and $0.24 \mathrm{~g}$ borate and making up to $100 \mathrm{~mL}$ with deionized water. Then $0.55 \mathrm{~g} \mathrm{CM}-\beta-\mathrm{CD}$ was weighed and added into the borate-phosphate buffer. After that, buffer $\mathrm{pH}$ was adjusted to 2.8 with $10 \%$ phosphoric acid. The BGE were prepared freshly every day and filtered through a $0.45 \mu \mathrm{M}$ hydrophilic cellulose membrane filter and degassed by sonication prior to use. The capillary was thermostated at $20{ }^{\circ} \mathrm{C}$. The samples were introduced by electrokinetic injection $(7.5 \mathrm{KV}$ for $20 \mathrm{~s})$ and run with the applying optimal voltage of $16 \mathrm{kV}$ with the current of about $80 \mu \mathrm{A}$. New uncoated fused-silica capillary was conditioned by flushing with $0.1 \mathrm{~mol} / \mathrm{L} \mathrm{NaOH}$ for $30 \mathrm{~min}$, and then rinsed with $0.1 \mathrm{~mol} / \mathrm{L} \mathrm{HCl}$ and water, respectively for $10 \mathrm{~min}$. Prior to each analysis, the capillary column was rinsed with $0.01 \mathrm{~mol} / \mathrm{L} \mathrm{NaOH}$ for $3 \mathrm{~min}$, and then water, followed by the BGE, each for $2 \mathrm{~min}$ between the runs.

\subsection{Preparation of Stock Solutions, Calibration Samples and Quality Control Samples}

Standard stock solution (1 $\mathrm{mg} / \mathrm{mL})$ of rac- MRT, DMR, 8-OHM, N-O-MRT and the IS were prepared in methanol, respectively. Working standard solutions (rang from 10 to $1000 \mathrm{ng} / \mathrm{mL}$ ) were prepared daily by diluting suitable aliquots of the stock solution to desired concentration with deionized water. The IS solution was prepared in deionized water at the concentration of $200 \mathrm{ng} / \mathrm{mL}$. The standard solutions were stored in brown glass vial to protect from light at $4{ }^{\circ} \mathrm{C}$.

Calibration samples were obtained by diluting standard working solutions $(20 \mu \mathrm{L})$ with drug-free human control plasma $(180 \mu \mathrm{L})$, to span a calibration standard range of $1-100 \mathrm{ng} / \mathrm{mL}$ for $\mathrm{rac}$-MRT, rac-DMR and rac-8-OHM. QC samples $(2,10,80 \mathrm{ng} / \mathrm{mL})$ for $r a c-M R T$, rac-DMR and rac-8-OHM were independently prepared by spiking appropriate amount of the working standard solution in drug-free human control plasma. 


\subsection{Preparation of Human Plasma Sample}

Plasma samples were pretreated using LLE in 96-well plates format. An electronic 96 channel handheld pipettor (INTEGRA Biosciences AG, CH-7205 Zizers, Switzerland) was used for liquid transfer steps. Two hundred $\mu \mathrm{L}$ of subject plasma samples, calibration samples and QC samples were spiked into a $2 \mathrm{~mL}$ deep 96-well plate, respectively. Aliquots of $20 \mu \mathrm{L}$ of $200 \mathrm{ng} / \mathrm{mL}$ IS solution were added to each well except for the well designated for the double blank plasma. Then $20 \mu \mathrm{L} 1 \mathrm{~mol} / \mathrm{L}$ $\mathrm{NaOH}$ were added to each well of the plate, and the plate was vortex mixed for $30 \mathrm{~s}$. After adding $1.0 \mathrm{~mL}$ of methyl tert-butyl ether, the plate was covered with a mat, vortex mixed for $5 \mathrm{~min}$, and centrifuged for $10 \mathrm{~min}$ at $3500 \mathrm{rpm}$. Next the mats were carefully removed and $0.8 \mathrm{~mL}$ of the supernatant organic layer was transferred from the original sample plates into the respective positions of new $2.0 \mathrm{~mL}$ deep 96-well plates. The plates were then placed into a self-constructed 96-well plate evaporator, and the organic extracts were evaporated to dryness with a nitrogen flow at $35{ }^{\circ} \mathrm{C}$. All dry residues were reconstituted by addition of $50 \mu \mathrm{L}$ ACN-water (80:20, v/v). Finally, the plates were vortex mixed for $5 \mathrm{~min}$, then centrifuged for $10 \mathrm{~min}$ at $3500 \mathrm{rpm}$, and the supernatant was transferred to the autosampler for injection onto the CE system.

\subsection{Clinical Pharmacokinetic Study}

The study protocol was formally accepted by China Food and Drug Administration and approved by a local ethics committee. Informed consent was obtained from all the subjects after explaining the aim and risks of the study. Twelve healthy Chinese male subjects with mean age $30 \pm 1.5$ years and average weight $64.3 \pm 6.5 \mathrm{~kg}$ were enrolled into the study. The volunteers received a single oral dose of $30 \mathrm{mg}$ racemic MRT tablets (Remeron ${ }^{\circledR}$, N.V. Organon, $30 \mathrm{mg} /$ tablet) around 8 a.m., with $200 \mathrm{~mL}$ of water after an overnight fasting. Blood samples $(1 \mathrm{~mL})$ were collected into heparinized centrifuge tubes at pre-dose $(0 \mathrm{~h})$ and at the time of $0.25,0.5,0.75,1,1.5,2,3,5,8,12,24,48,72$ and $96 \mathrm{~h}$ after administration. Plasma was separated by centrifugation $(4,000 \times g)$ for $10 \mathrm{~min}$ at $4{ }^{\circ} \mathrm{C}$ and frozen at $-80{ }^{\circ} \mathrm{C}$ until analysis.

\section{Conclusion}

An easy, cost effective, rapid and highly sensitive ACN-FASS CZE method has been validated and proposed for the simultaneous in vitro enantioselective analysis of MRT and its three metabolites for the first time, which was recommended to be adopted for analyzing pharmacokinetic profiles of MRT in human subjects. CM- $\beta-\mathrm{CD}$ was selected as chiral additive and the optimization procedure demonstrated that electrokinetic injection in conjunction with dissolving the sample in $80 \%$ ACN yields better stacking and provided a sensitivity enhancement of about 50-60 folds. After LLE in 96-well plates format, the enantiomers in plasma samples as low as $0.5 \mathrm{ng} / \mathrm{mL}$ for MRT, DMR and 8-OHM were able to be separated and detected by CZE with the aid of ACN-FASS within 7 min. The developed and validated method was applied to a stereoselective pharmacokinetics study of MRT and its metabolites in healthy volunteers after oral administration of MRT. 


\section{Acknowledgements}

This work was supported by Pharmacokinetics Platform of the Innovation Drug Research founded by Ministry of Science and Technology of P.R. China (Grant No. 2009ZX09301-011), the National Natural Science Foundation of China (No. 81001420).

\section{Author Contributions}

Jun Wen, Wen-Ting Zhang, Wei-Qun Cao and Guo-Rong Fan conceived of this study and designed the experiments. Jun Wen, Wen-Ting Zhang, Wei-Qun Cao and Ji Li performed the experiments. All the authors analyzed the data and discussed the results. Jun Wen and Wen-Ting Zhang drafted the manuscript with the help of Guo-Rong Fan. All the authors have read and approved the final manuscript.

\section{Conflicts of Interest}

The authors declare no conflict of interest.

\section{References}

1. Anttila, S.A.; Leinonen, E.V. A review of the pharmacological and clinical profile of mirtazapine. CNS. Drug. Rev. 2001, 7, 249-264.

2. Montgomery, S. Safety of mirtazapine: A review. Int. Clin. Psychopharmacol. 1995, 10, 37-45.

3. Fawcett, J.; Barkin, R.L. Review of the results from clinical studies on the efficacy, safety and tolerability of mirtazapine for the treatment of patients with major depression. J. Affect. Disord. 1998, 51, 267-285.

4. Timmer, C.J.; Sitsen, J.A.; Delbressine, L.P. Clinical pharmacokinetics of mirtazapine. Clin. Pharmacokinet. 2000, 38, 461-474.

5. De Boer, T. The pharmacologic profile of mirtazapine. J. Clin. Psychiat. 1996, 57, 19-25.

6. Quimby, J.M.; Gustafson, D.L.; Lunn, K.F. The pharmacokinetics of mirtazapine in cats with chronic kidney disease and in age-matched control cats. J. Vet. Intern. Med. 2011, 25, 985-989.

7. Giorgi, M.; Yun, H. Pharmacokinetics of mirtazapine and its main metabolites in Beagle dogs: A pilot study. Vet. J. 2012, 192, 239-241.

8. Giorgi, M.; Owen, H. Mirtazapine in veterinary medicine a pharmacological rationale for its application in chronic pain. Am. J. Anim. Vet. Sci. 2012, 7, 42-47.

9. Rouini, M.R.; Lavasani, H.; Sheikholeslami, B.; Nikoui, V.; Bakhtiarian, A.; Sgorbini, M.; Giorgi, M. Pharmacokinetics of mirtazapine and its main metabolites after single oral administration in fasting/Fed horses. J. Equine Vet. Sci. 2013, 33, 410-414.

10. Dahl, M.L.; Voortman, G.; Alm, C.; Elwin, C.E.; Delbressine, L.; Vos, R.; Bogaards, J.; Bertilsson, L. In vitro and in vivo studies on the disposition of mirtazapine in humans. Clin. Drug Invest. 1997, 13, $37-46$.

11. Grasmäder, K.; Verwohlt, P.L.; Kühn, K.U.; Dragicevic, A.; von Widdern, O.; Zobel, A.; Hiemke, C.; Rietschel, M.; Maier, W.; Jaehde, U. Population pharmacokinetic analysis of mirtazapine. Eur. J. Clin. Pharmacol. 2004, 60, 473-480. 
12. Delbressine, L.; Moonen, M.; Kaspersen, F.; Wagenaars, G.; Jacobs, P.; Timmer, C.; Paanakker, J.; van Hal, H.; Voortman, G. Pharmacokinetics and biotransformation of mirtazapine in human volunteers. Clin. Drug Invest. 1998, 15, 45-55.

13. Dodd, S.; Boulton, D.W.; Burrows, G.D.; Vane, D.; Lindsay, C.; Norman, T.R. In vitro metabolism of mirtazapine enantiomers by human cytochrome P450 enzymes. Hum. Psychopharmacol. Clin. Exp. 2001, 16, 541-544.

14. De Santana, F.J.M.; de Oliveira, A.R.M.; Bonato, P.S. Chiral liquid chromatographic determination of mirtazapine in human plasma using two-phase liquid-phase microextraction for sample preparation. Anal. Chim. Acta 2005, 549, 96-103.

15. Dodd, S.; D Burrows, G.; Norman, T.R. Chiral determination of mirtazapine in human blood plasma by high-performance liquid chromatography. J. Chromatogr. B Biomed. Sci. Appl. 2000, 748, 439-443.

16. De Santana, F.J.M.; Cesarino, E.J.; Bonato, P.S. New method for the chiral evaluation of mirtazapine in human plasma by liquid chromatography. J. Chromatogr. B 2004, 809, 351-356.

17. Fanali, S.; Aturki, Z.; Raggi, M.A.; D’Orazio, G. Enantiomeric separation of mirtazapine and its metabolites by nano-liquid chromatography with UV-absorption and mass spectrometric detection. J. Sep. Sci. 2005, 28, 1719-1728.

18. Rao, R.N.; Kumar, K.N.; Ramakrishna, S. Enantiomeric separation of mirtazapine and its metabolite in rat plasma by reverse polar ionic liquid chromatography using fluorescence and polarimetric detectors connected in series. J. Chromatogr. B 2011, 879, 1911-1916.

19. Paus, E.; Jonzier-Perey, M.; Cochard, N.; Eap, C.B.; Baumann, P. Chirality in the new generation of antidepressants: Stereoselective analysis of the enantiomers of mirtazapine, $N$-demethylmirtazapine, and 8-hydroxymirtazapine by LC-MS. Ther. Drug Monit. 2004, 26, 366-374.

20. De Santana, F.J.M.; Jabor, V.A.P.; Cesarino, E.J.; Lanchote, V.L.; Bonato, P.S. Enantioselective analysis of mirtazapine, demethylmirtazapine and 8-hydroxy mirtazapine in human urine after solid-phase microextraction. J. Sep. Sci. 2010, 33, 268-276.

21. De Santana, F.J.M.; Bonato, P.S. Enantioselective analysis of mirtazapine and its two major metabolites in human plasma by liquid chromatography-mass spectrometry after three-phase liquid-phase microextraction. Anal. Chim. Acta 2008, 606, 80-91.

22. Mandrioli, R.; Pucci, V.; Sabbioni, C.; Bartoletti, C.; Fanali, S.; Raggi, M.A. Enantioselective determination of the novel antidepressant mirtazapine and its active demethylated metabolite in human plasma by means of capillary electrophoresis. J. Chromatogr. A 2004, 1051, 253-260.

23. De Santana, F.J.M.; Lanchote, V.L.; Bonato, P.S. Capillary electrophoretic chiral determination of mirtazapine and its main metabolites in human urine after enzymatic hydrolysis. Electrophoresis 2008, 29, 3924-3932.

24. Aturki, Z.; Scotti, V.; D’Orazio, G.; Rocco, A.; Raggi, M.A.; Fanali, S. Enantioselective separation of the novel antidepressant mirtazapine and its main metabolites by CEC. Electrophoresis 2007, 28, 2717-2725.

25. Everaerts, F.M.; Verheggen, T.P.; Mikkers, F.E. Determination of substances at low concentrations in complex mixtures by isotachophoresis with column coupling. J. Chromatogr. A 1979, 169, $21-38$. 
26. Shihabi, Z.K. Organic solvent high-field amplified stacking for basic compounds in capillary electrophoresis. J. Chromatogr. A 2005, 1066, 205-210.

27. Li, J.; Li, Y.; Zhang, W.; Chen, Z.; Fan, G. Glucose- $\beta$-CD interaction assisted ACN field-amplified sample stacking in CZE for determination of trace amlodipine in beagle dog plasma. J. Sep. Sci. 2013, 36, 1817-1825.

28. Li, J.; Bi, Y.; Wang, L.; Sun, F.; Chen, Z.; Xu, G.; Fan, G. $\beta$-Cyclodextrin enhanced on-line organic solvent field-amplified sample stacking in capillary zone electrophoresis for analysis of ambroxol in human plasma, following liquid-liquid extraction in the 96-well format. J. Pharm. Biomed. Anal. 2012, 66, 218-224.

29. Chen, C.C.; Wu, S.M.; Huang, Y.H.; Ko, W.K.; Kou, H.S.; Wu, H.L. On-line field-amplified sample stacking in capillary electrophoresis for analysis of amitriptyline and its metabolite nortriptyline in plasma. Anal. Chim. Acta 2004, 517, 103-110.

30. Tsioupi, D.A.; Stefan-vanStaden, R.I.; Kapnissi-Christodoulou, C.P. Chiral selectors in CE: Recent developments and applications. Electrophoresis 2013, 34, 178-204.

31. Quirino, J.P.; Terabe, S. Approaching a million-fold sensitivity increase in capillary electrophoresis with direct ultraviolet detection: Cation-selective exhaustive injection and sweeping. Anal. Chem. 2000, 72, 1023-1030.

32. Simpson, S.L., Jr; Quirino, J.P.; Terabe, S. On-line sample preconcentration in capillary electrophoresis: Fundamentals and applications. J. Chromatogr. A 2008, 1184, 504-541.

33. Quirino, J.P.; Terabe, S. Sample stacking of cationic and anionic analytes in capillary electrophoresis. J. Chromatogr. A 2000, 902, 119-135.

34. Chien, R.L.; Helmer, J.C. Electroosmotic properties and peak broadening in field-amplified capillary electrophoresis. Anal. Chem. 1991, 63, 1354-1361.

35. Liao, H.W.; Lin, S.W.; Wu, U.I.; Kuo, C.H. Rapid and sensitive determination of posaconazole in patient plasma by capillary electrophoresis with field-amplified sample stacking. J. Chromatogr. A 2012, 1226, 48-54.

Sample Availability: Samples of the compounds MRT and DMR are available from the authors.

(C) 2014 by the authors; licensee MDPI, Basel, Switzerland. This article is an open access article distributed under the terms and conditions of the Creative Commons Attribution license (http://creativecommons.org/licenses/by/3.0/). 